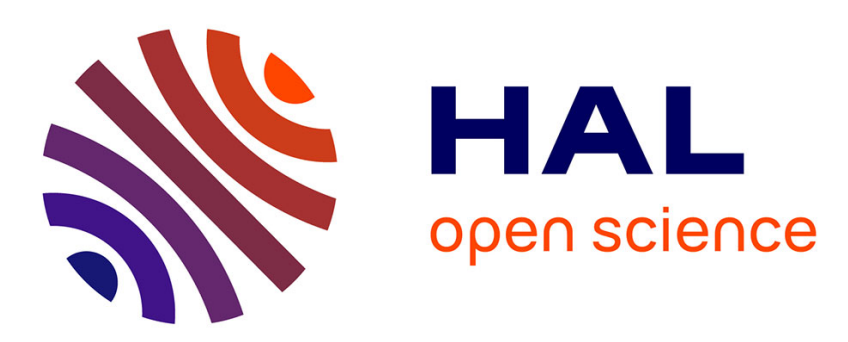

\title{
Cold atmospheric plasma-induced acidification of tissue surface: visualization and quantification using agarose gel models
}

\author{
Giovanni Busco, Azadeh Valinataj Omran, Loick Ridou, Jean-Michel \\ Pouvesle, Eric Robert, Catherine Grillon
}

\section{To cite this version:}

Giovanni Busco, Azadeh Valinataj Omran, Loick Ridou, Jean-Michel Pouvesle, Eric Robert, et al.. Cold atmospheric plasma-induced acidification of tissue surface: visualization and quantification using agarose gel models. Journal of Physics D: Applied Physics, 2019, 52 (24), pp.24LT01. 10.1088/13616463/ab1119 . hal-02089383

\section{HAL Id: hal-02089383 https://hal.science/hal-02089383}

Submitted on 23 Nov 2020

HAL is a multi-disciplinary open access archive for the deposit and dissemination of scientific research documents, whether they are published or not. The documents may come from teaching and research institutions in France or abroad, or from public or private research centers.
L'archive ouverte pluridisciplinaire HAL, est destinée au dépôt et à la diffusion de documents scientifiques de niveau recherche, publiés ou non, émanant des établissements d'enseignement et de recherche français ou étrangers, des laboratoires publics ou privés. 


\title{
Cold atmospheric plasma-induced acidification of tissue surface: visualization and quantification using agarose gel models
}

Giovanni Busco', Azadeh Valinataj Omran², Loïck Ridou', Jean-Michel Pouvesle², Eric Robert $^{2}$ and Catherine Grillon ${ }^{1}$

${ }^{1}$ Centre de Biophysique Moléculaire, UPR4301CNRS, 45071 Orléans, France

${ }^{2}$ GREMI, UMR 7344 CNRS/University of Orléans, 45067 Orléans, France

\begin{abstract}
The biological effects induced by cold atmospheric plasmas (CAPs) on human tissues are mainly due to the production of reactive oxygen and nitrogen species (RONS). Some RONS are also responsible for $\mathrm{pH}$ lowering of the treated medium. The CAP-induced acidification has beneficial effect on biological tissues, contributing to the anti-bacterial effect and to the healing improvement observed in treated wound. In this work we investigated the local acidification induced by a helium CAP treatment using tissue models made of agarose gels with adjusted $\mathrm{pH}$ around 7.4 to mimic generic organs or around 5.5 to simulate skin surface $\mathrm{pH}$. Using fluorescein as a $\mathrm{pH}$-sensitive fluorescent marker, we developed a useful technique to visualize and quantify the local acidification induced by CAP exposure of tissue surface. The different capillaries used to produce the plasma jet, the treatment time, the initial $\mathrm{pH}$ of the surface and the buffer capacity of the tissue model were shown to modulate both the size of the impacted surface and the intensity of the $\mathrm{pH}$ decrease. The proposed technique can be advantageous to study the acidifying effect induced by plasma. This method can help to plan safe and controlled plasma treatments in order to avoid hyper-acidification of the tissue, especially when a localized treatment is administered.
\end{abstract}

Keywords: plasma, CAP, pH measurement, fluorescence, fluorescein, agarose model 
Today cold plasmas generated at atmospheric pressure (CAPs) are extensively exploited for biomedical applications [1, 2]. Dermocosmetic research is one of the most promising fields of plasma medicine [3]. The encouraging results obtained in wound disinfection and healing and the easy accessibility of this external organ, make the skin a privileged target for plasma treatments [4]. In dermatology, CAPs have been already employed in clinical trials to treat mainly infected wounds. Their use for cosmetic purposes is much more recent and still at the research level. For this type of application, the safety of treatment conditions is primordial and requires various in vitro studies before passing to in vivo treatments. Several models have been proposed to mimic and study the skin properties in vitro [5]. Among these, gelatin and agarose are the most used for plasma treatments [6,7]. The biological effect of CAPs reside mostly in RONS production. Quantification and distribution of these species inside the target is crucial to plan the convenient plasma treatment. RONS detection in liquids is commonly performed in liquids thanks to the plethora of commercially available probes. Conversely, direct RONS quantification inside semi-solid targets like gelatin or agarose is more complex. Kawasaki and collaborators employed the iodine test (KI-starch) to visualize RONS generation in agarose upon CAP treatment [8]. Dobrynin and colleagues, used agarose gel to visualize the penetration depth of plasma-generated hydrogen peroxide and, in the same work, they used fluorescein added to agarose gel to demonstrate the plasmainduce $\mathrm{pH}$ decrease inside the target [6]. CAP-induced acidification in media is a known effect, the $\mathrm{pH}$ drop is being mainly due to the generation of acid species like nitrous and nitric acid $[9,10]$. The acidification degree depends on CAP parameters (frequency, gas flow rate and exposure time) and on the buffer capacity of the medium. CAP treatment has been shown to significantly increase acidification of skin [11]. Today, to measure skin $\mathrm{pH}, \mathrm{pH}$ meters with flat electrodes are conveniently used [12]. Although these instruments give precise measurements of $\mathrm{pH}$, the recorded value is the average of the hydrogen ion concentration on the whole surface underneath the electrode, i.e. at least one centimeter square. When a tissue is treated with a plasma-jet, the CAP impacted zone is exposed to the highest concentration of chemical species. In such "focalized" treatments, the $\mathrm{pH}$ on the exposed area can dramatically decrease generating chemical burns and permanent damages. Understanding how CAP generated species are delivered in an organ or in intact skin is of a crucial importance in order to propose a safe treatment. In this work we used agarose gels as models to mimic human tissues. Two models with different $\mathrm{pH}$ were used: one having a pH around 7.4 to mimic most of human tissues and the other having a $\mathrm{pH}$ around 5.5 to simulate the outer layers of the skin. In order to visualize and quantify the local acidification induced by CAP in these models, we pre-mixed fluorescein to the agarose gels. We took advantage of the fluorophore fluorescein for its well-known $\mathrm{pH}$-dependent fluorescence [13-15]. In fact, fluorescein coupled to gelatin was previously used to measure localized acidification induced by cancer cells in Matrigel ${ }^{\circledR}$ [16]. Thanks to its very low toxicity, fluorescein can also be used as an internal tracer in human body and has been proposed for the non-invasive measurement of retinal $\mathrm{pH}$ [17]. Concerning plasma, an attempt to qualitatively demonstrate the $\mathrm{pH}$ drop induced by CAP in fluorescein-containing agarose was formerly done [6] but the precise extend of $\mathrm{pH}$ decrease and the impacted area remain to be studied.

In this work, we used sodium fluorescein imbedded in a $2 \%$ agarose gel to mimic human tissues. Agarose was dissolved either on a physiologic saline solution ( $\mathrm{NaCl} 150 \mathrm{mM})$ or in a slightly buffered saline solution ( $\mathrm{NaCl} 150 \mathrm{mM}$, HEPES $5.5 \mathrm{mM}$ ). The buffered or non- 
buffered solutions were adjusted to different $\mathrm{pH}$. Six solutions with $\mathrm{pH}$ ranging from 7.4 to 2.5 were used for establishment of the calibration curve. After adding agarose (2\%) and fluorescein $(50 \mu \mathrm{M})$ to each solution, the resulting mixtures were gently heated in a microwave and poured in 6-well plates. The volume was calculated in order to get a $2 \mathrm{~mm}$ thick gels in each well. The fluorescent gel at $\mathrm{pH}$ around 7.4 was used as a model for generic organ while the gel $\mathrm{pH} 5.5$ was used as a skin model [18]. Plasma treatment was carried out using the previously described helium Plasma Gun device [19, 20] already assessed for in vivo experiments [21].

To study the impact of the jet on the plasma exposed target, two different glass capillaries were used: a straight capillary with an internal diameter of $4 \mathrm{~mm}$ and a capillary having a tapered extremity with an inner diameter of $1.5 \mathrm{~mm}$. The tip of the capillary was set at $10 \mathrm{~mm}$ above the gel surface. Each treatment was performed for $120 \mathrm{~s}$ or $300 \mathrm{~s}$, at a frequency of 1 $\mathrm{kHz}$ and a helium gas flow rate set at $0.5 \mathrm{~L} / \mathrm{min}$. For each experiment, three fluorescence intensity images of the agarose-containing wells were acquired: before the treatment, immediately after plasma exposure and 10 min after plasma exposure, using the Typhoon ${ }^{\mathrm{TM}}$ FLA 9500 biomolecular imager (GE Healthcare Life Science) equipped with a $473 \mathrm{~nm}$ (blue LD laser) and a Y520 emission filter (wavelength range $\geq 520 \mathrm{~nm}$ ). High quality pictures were acquired with a pixel size of $100 \mu \mathrm{m}$. Images were exported and processed in ImageJ. Real dimension of the 8-Bit grey scale images were assigned in $\mathrm{mm}$ units using the set scale function. The background variations and the drift of fluorescence that can occur during the three consecutive scans were measured and corrected. For a qualitative and visual analysis of the acidification induced by plasma, images were converted in pseudocolors using the ICA3 option in Lookup Tables. The fluorescence intensity of the 6 wells was quantified and the measured integrated density values were assigned to the known pH values. A calibration curve of the gray scale values vs $\mathrm{pH}$ was obtained using the roadboard function (Figure 1). To measure $\mathrm{pH}$ evolution before and after the treatment in our models, a straight line selection of $18-22 \mathrm{~mm}$, passing through the center of the treated area, was manually traced. A plot profile of fluorescence intensity showing $\mathrm{pH}$ variations along the traced line was obtained. Data from each plot profile can be exported in excel or other spreadsheet software for further analysis. In this paper we used the software GraphPad Prism version 6 and GIMP for chart and figure design respectively.

The effect of CAP treatment on $\mathrm{pH}$ modulation was first studied in agarose gel without buffer capacity. Non-buffered agar models mimicking generic organs $(\mathrm{pH} 7.4)$ or skin $(\mathrm{pH} 5.5)$ were treated for 120 s with plasma-gun using either a straight or a tapered capillary (Figure 2). When a tapered capillary was used, the thin plasma jet (diameter $<1 \mathrm{~mm}$ ) induces a focalized $\mathrm{pH}$ drop (Figure $2 \mathrm{a}$ ) either in the generic organ (4 pH units) or in the skin model (3 pH units). Interestingly, the $\mathrm{pH}$ dropped to a value around 3 either in the neutral or in the already acidic model. It is known that during plasma treatment one of the acidic species produced is nitrous acid. This weak acid has a pKa 3.16 [22]. We can speculate that the nitrous acid locally produced creates a buffer at $\mathrm{pH} 3$ keeping the $\mathrm{pH}$ more stable around this value when a short treatment is administered. A similar $\mathrm{pH}$ drop, in a non-buffered saline, was already showed by Hänsch et al; at this $\mathrm{pH}$ values, plasma treated solution has been shown to exert a potent bactericidal effect [23]. When the straight capillary was used (Figure 2b), the larger plasma jet led to a minor and uniform acidification in the generic organ and the skin model (1 $\mathrm{pH}$ units in both cases). In all the treatments, very slight $\mathrm{pH}$ variations were registered $10 \mathrm{~min}$ 
after plasma exposure. We measured the diameter of the acidified surface generated with the two capillaries. The skin model, exposed to the jet generated by the tapered capillary, shows an acidified surface with a diameter 1.5 times larger than the one measured on the generic organ model (12 mm vs $8 \mathrm{~mm}$ ) and 2 times larger $(12 \mathrm{~mm}$ vs $6 \mathrm{~mm}$ ) when the straight capillary is used. It appears that the acidic species spreads better in the already acidic model.

The observed acidification could overestimate the real acidifying effect induced by CAP on human tissues. In fact, human organs possess buffer systems that offset $\mathrm{pH}$ variations to maintain physiological values [24]. The skin, in its outer layers possesses its own buffer system [25]. In order to improve our models, we prepared fluorescein-containing gels with a HEPES-based buffer system. In figure 3, buffered-fluorescent agarose models were exposed to CAP using the tapered capillary. When the buffered gel was exposed for 120 s to plasma treatment, we measured a minor $\mathrm{pH}$ decrease respect the one measured previously in the non-buffered agarose. The generic organ model (figure 3a) shows a drop of just $1.5 \mathrm{pH}$ units while the skin model decreases its $\mathrm{pH}$ of $1 \mathrm{pH}$ units (fig. $3 \mathrm{~b}$ ). A longer treatment of 300 s results in a higher $\mathrm{pH}$ decrease in the generic organ model $(2.5 \mathrm{pH}$ units) and a weaker decrease in the skin model (1.5 pH units). In figure 4, we exposed agarose models to plasma, using a straight capillary. When the buffered-generic organ model was exposed to the jet generated with this capillary, we observed almost no $\mathrm{pH}$ variation for the short treatment of $120 \mathrm{~s}$ and a very little $\mathrm{pH}$ drop, less than $0.5 \mathrm{pH}$ units, for the longer treatment of 300 s (Figure 4a). The treatment of the skin model using the straight capillary (Figure 4b) results in a pH drop, around 0.5 and $1 \mathrm{pH}$ units for short and long CAP treatment respectively, the measured acidification appearing weaker compared to the one observed using the tapered capillary. As observed in the non-buffered system, the treatment of the skin model results in a wider acidified surface, on average 1.4 times larger ( $9.7 \mathrm{~mm}$ vs $6.7 \mathrm{~mm}$ ). In conclusion, the presented method permits not only to visualize in situ acidification but also to quantify the $\mathrm{pH}$ changes, in the range of 2.5 to $7.4 \mathrm{pH}$ units. Although the described method can have some limitations and weakness, it offers the advantage of measuring the $\mathrm{pH}$ on a very small spot. To date the precise measurement of these limited surfaces using flat $\mathrm{pH}$-meters is not possible. These $\mathrm{pH}$-meters, whose smaller probe surface is around 1 $\mathrm{cm}^{2}$, can only give a $\mathrm{pH}$ mean value of the whole covered surface. We demonstrated here that this novel technique can help understanding the impact of a plasma treatment on a biological tissue to better plan in vivo plasma therapy. In fact, these results show how different parameters such as the capillary shape, the treatment time, the initial $\mathrm{pH}$ and the buffer capacity of the tissue model can influence the plasma-induced acidification in a treated tissue. Particularly, the diameter of the plasma jet was shown to induce an impact on the acidic species distribution on the treated surface, suggesting that large jet can be used to have a diffuse and uniform treatment while thin jets can be useful to focalize the treatment without disturbing the surrounding tissue $\mathrm{pH}$.

\section{Aknowledgments}

This work was supported by Cosmetosciences, a global training and research program dedicated to the cosmetic industry, located in the heart of the Cosmetic Valley, this program led by University of Orléans is funded by the Région Centre-Val de Loire, France. Giovanni 
Busco, Azadeh Valinataj Omran and Loïck Ridou are supported by Cosmetosciences (PLASMACOSM Project, Grant 2015-00103497). This work was performed in the frame of the French CNRS networks, GDR2025 HAPPYBIO and GDR3711 Cosmactifs. The authors thank Dr Endré Szili, University of South Australia, for stimulating discussions during the Expert Days funded by Le Studium

1. Laroussi, M. and X. Lu, Room-temperature atmospheric pressure plasma plume for biomedical applications. Applied Physics Letters, 2005. 87(11): p. 113902.

2. Kong, M.G., et al., Plasma medicine: an introductory review. New Journal of Physics, 2009. 11(11): p. 115012.

3. Heinlin, J., et al., Plasma applications in medicine with a special focus on dermatology. J Eur Acad Dermatol Venereol, 2011. 25(1): p. 1-11.

4. Haertel, B., et al., Non-thermal atmospheric-pressure plasma possible application in wound healing. Biomol Ther (Seoul), 2014. 22(6): p. 477-90.

5. Dąbrowska, A.K., et al., Materials used to simulate physical properties of human skin. Skin Research and Technology, 2016. 22(1): p. 3-14.

6. Dobrynin, D., et al., Deep Penetration into Tissues of Reactive Oxygen Species Generated in Floating-Electrode Dielectric Barrier Discharge (FE-DBD): An <i>In Vitro</i> Agarose Gel Model Mimicking an Open Wound. 2012. 2(1-3): p. 71-83.

7. Szili, E.J., et al., Tracking the Penetration of Plasma Reactive Species in Tissue Models. Trends in Biotechnology, 2018. 36(6): p. 594-602.

8. Kawasaki, T., et al., Visualization of the Distribution of Oxidizing Substances in an Atmospheric Pressure Plasma Jet. IEEE Transactions on Plasma Science, 2014. 42(10): p. 2482-2483.

9. Chen, C.-W., H.-M. Lee, and M.-B. Chang, Influence of $\mathrm{pH}$ on inactivation of aquatic microorganism with a gas-liquid pulsed electrical discharge. Journal of Electrostatics, 2009. 67(4): p. 703-708.

10. Oehmigen, K., et al., The Role of Acidification for Antimicrobial Activity of Atmospheric Pressure Plasma in Liquids. Plasma Processes and Polymers, 2010. 7(3-4): p. 250-257.

11. Heuer, K., et al., The topical use of non-thermal dielectric barrier discharge (DBD): nitric oxide related effects on human skin. Nitric Oxide, 2015. 44: p. 52-60.

12. du Plessis, J.L., A.B. Stefaniak, and K.P. Wilhelm, Measurement of Skin Surface pH. Curr Probl Dermatol, 2018. 54((pH of the Skin: Issues and Challenges)): p. 19-25.

13. Emmart, E.W., Observations on the absorption spectra of fluorescein, fluorescein derivatives and conjugates. Archives of Biochemistry and Biophysics, 1958. 73(1): $p$. 1-8.

14. Leonhardt, H., L. Gordon, and R. Livingston, Acid-base equilibriums of fluorescein and 2', 7'-dichlorofluorescein in their ground and fluorescent states. The Journal of Physical Chemistry, 1971. 75(2): p. 245-249.

15. Martin, M.M. and L. Lindqvist, The $\mathrm{pH}$ dependence of fluorescein fluorescence. Journal of Luminescence, 1975. 10(6): p. 381-390.

16. Busco, G., et al., NHE1 promotes invadopodial ECM proteolysis through acidification of the peri-invadopodial space. FASEB J, 2010. 24(10): p. 3903-15.

17. Martin, H., et al., Sodium fluorescein as a retinal $\mathrm{pH}$ indicator? Physiological Measurement, 2005. 26(4): p. N9.

18. Mauro, T., et al., Barrier recovery is impeded at neutral $\mathrm{pH}$, independent of ionic effects: implications for extracellular lipid processing. Archives of Dermatological Research, 1998. 290(4): p. 215-222.

19. Robert, E., et al., Characterization of pulsed atmospheric-pressure plasma streams (PAPS) generated by a plasma gun. Plasma Sources Science and Technology, 2012. 21(3): p. 034017. 
20. Busco, G., et al., Changes in Oxygen Level Upon Cold Plasma Treatments: Consequences for RONS Production IEEE Trans Radiat Plasma Med Sci., 2018. 2(2): p. 147-152.

21. Collet, G., et al., Plasma jet-induced tissue oxygenation: potentialities for new therapeutic strategies. Plasma Sources Science and Technology, 2014. 23(1): p. 012005.

22. da Silva, G., E.M. Kennedy, and B.Z. Dlugogorski, Ab Initio Procedure for AqueousPhase pKa Calculation: The Acidity of Nitrous Acid. The Journal of Physical Chemistry A, 2006. 110(39): p. 11371-11376.

23. Hänsch, M.A.C., et al., Analysis of antibacterial efficacy of plasma-treated sodium chloride solutions. Journal of Physics D: Applied Physics, 2015. 48(45): p. 454001

24. Hamm, L.L., N. Nakhoul, and K.S. Hering-Smith, Acid-Base Homeostasis. Clinical journal of the American Society of Nephrology : CJASN, 2015. 10(12): p. 2232-2242.

25. Zhai, $\mathrm{H}$., et al., Measuring human skin buffering capacity: an in vitro model. Skin Research and Technology, 2009. 15(4): p. 470-475.

\section{FIGURES}

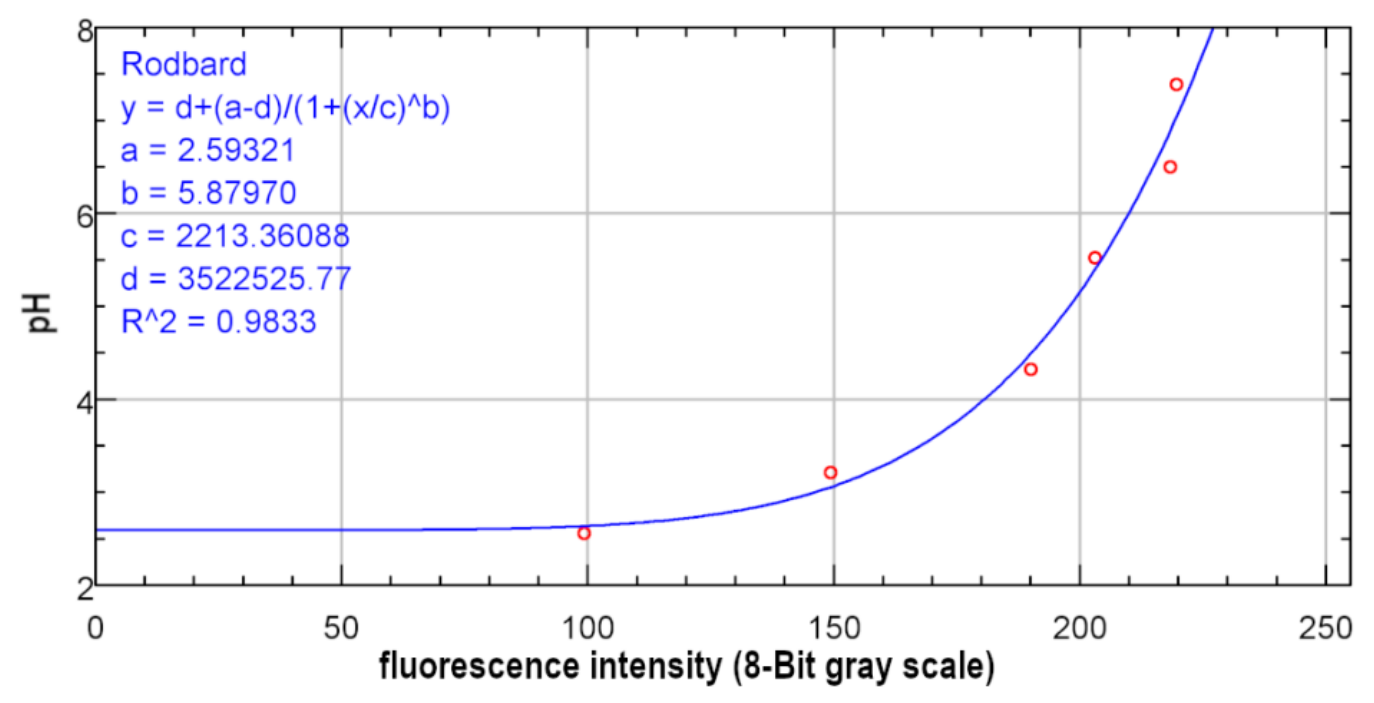

Figure 1. A typical roadboard calibration curve of fluorescein fluorescence intensity vs pH obtained in ImageJ. 
a) CAP using a tapered capillary
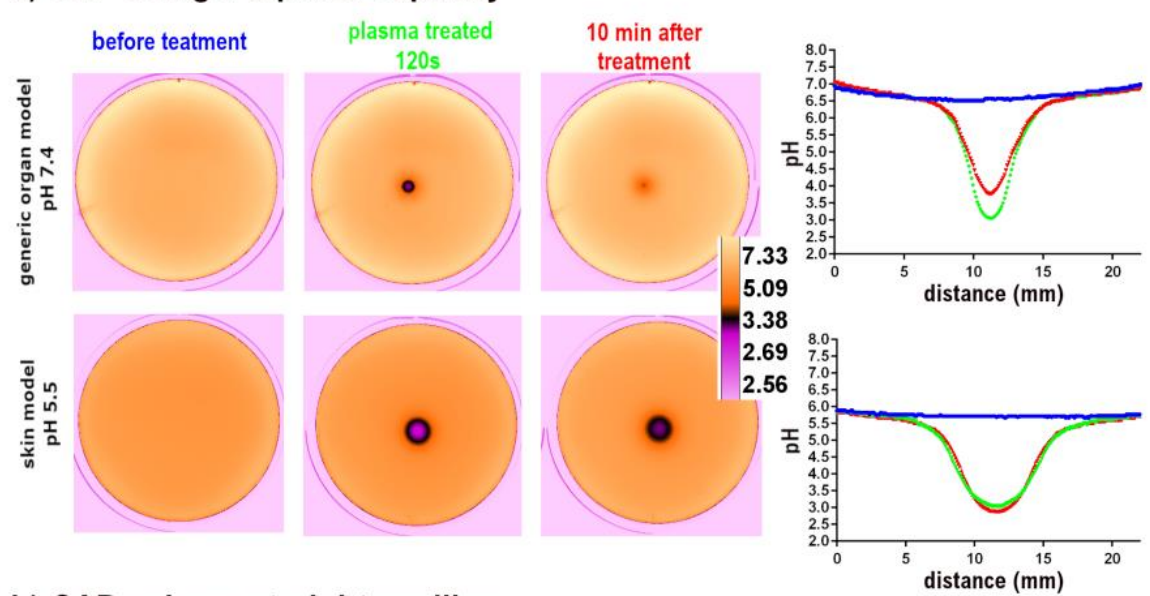

b) CAP using a straight capillary

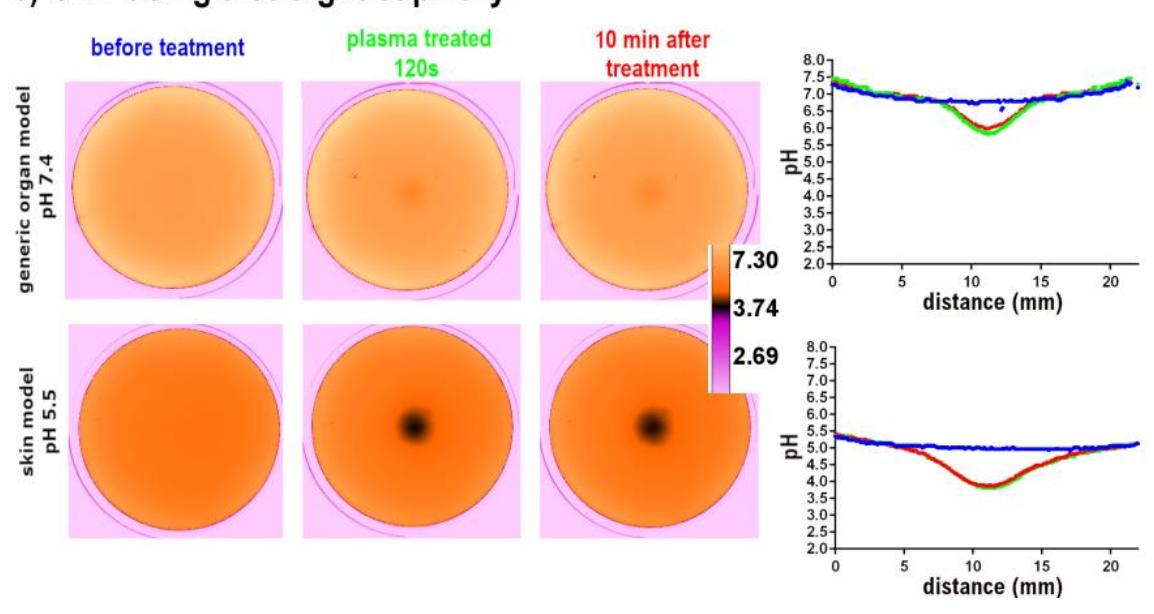

Figure 2. Non-buffered fluorescent agarose gels, with initial physiological around 7.4 or 5.5 , treated with CAP using a tapered (a) or a straight capillary (b) to generate the plasma-jet. The fluorescence emission of the agarose gel was acquired as 8-Bit gray scale images and converted in ICA3 pseudocolor to better visualize the acidified area, the $\mathrm{pH}$ pseudocolor calibration bar is shown on the right of the images. On the right part of the figure the $\mathrm{pH}$ plots graphs measured before (blue trace), immediately after plasma treatment (green trace) and $10 \mathrm{~min}$ after plasma treatment (red trace) 


\section{CAP using a tapered capillary}
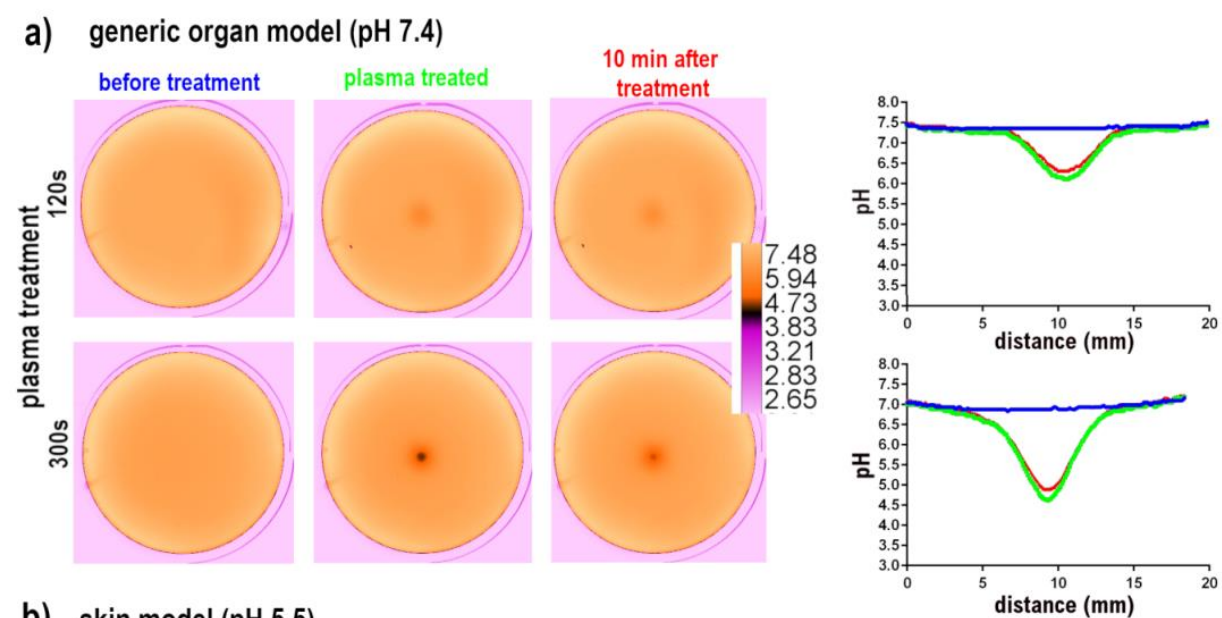

b) skin model (pH 5.5)
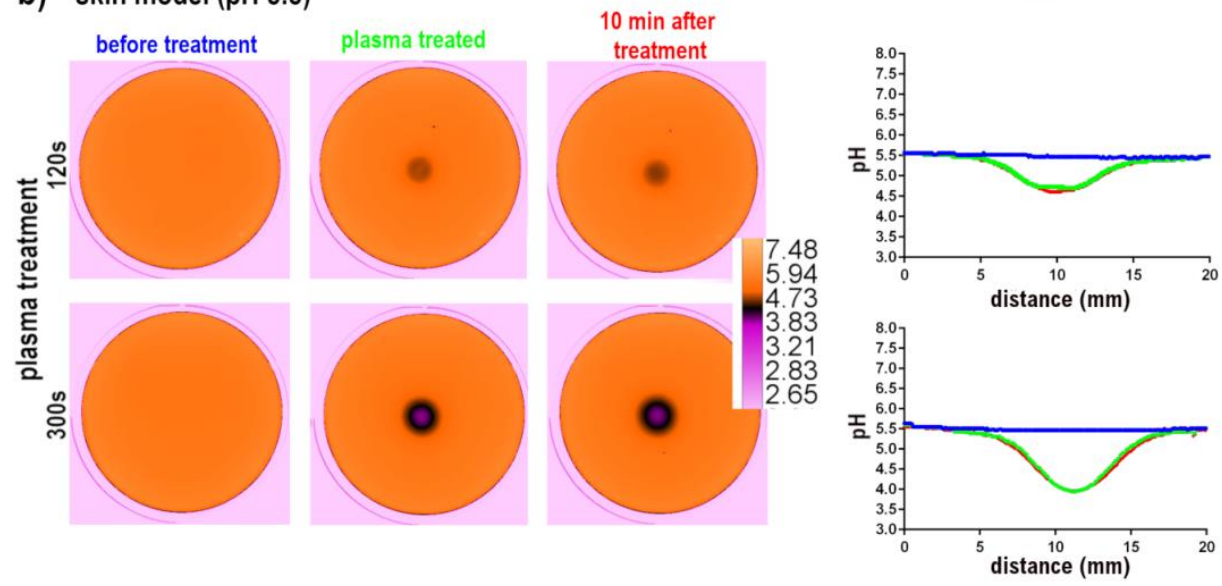

262 Figure 3. Buffered fluorescent agarose gels mimicking a generic organ $\mathrm{pH}$ (a) or skin (b) treated with CAP for 120 s or 300 s using a tapered capillary to generate the plasma-jet. The fluorescence emission of the agarose gel was acquired as 8-Bit gray scale images and converted in ICA3 pseudocolor to better visualize the acidified area, the $\mathrm{pH}$ pseudocolor calibration bar is shown on the right of the images. On the right part of the figure the $\mathrm{pH}$ plots graphs measured before (blue trace), immediately after (green trace) and 10 min after plasma treatment (red trace) 


\section{CAP using a straight capillary}

\section{a) generic organ model ( $\mathrm{pH} 7.4)$}

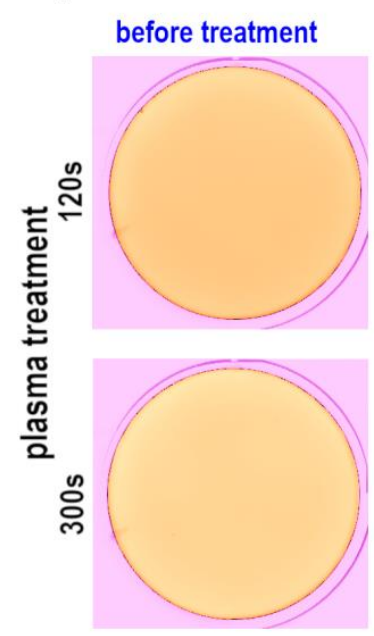

b) skin model (pH 5.5)

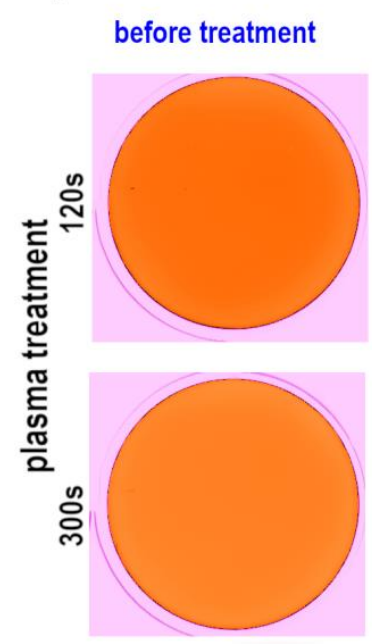

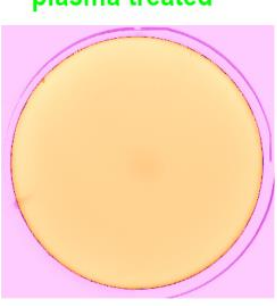

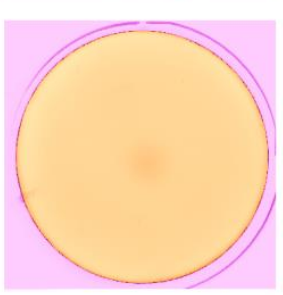

plasma treated

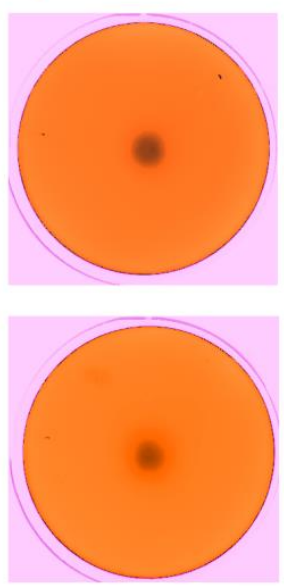

Figure 4. Buffered fluorescent agarose gels mimicking a generic organ $\mathrm{pH}(\mathrm{a})$ or skin (b) treated with CAP for 120 s or 300 s using a straight capillary to generate the plasma-jet. The fluorescence emission of the agarose gel was acquired as 8-Bit gray scale images and converted in ICA3 pseudocolor to better visualize the acidified area, the $\mathrm{pH}$ pseudocolor calibration bar is shown on the right of the images On the right part of the figure the $\mathrm{pH}$ plots graphs measured before (blue trace), immediately after (green trace) and 10 min after plasma treatment (red trace) 
